\title{
Impact of A Psycho-Education Intervention on Insight of Hospitalized Schizophrenic Patients
}

\author{
Ghada Ahmed Ghazi, Magdala Habib Farid Maximos, Sanaa Abdel Aziz Imam
}

\begin{abstract}
Severely impaired insight is one of the main characteristics of psychotic disorders that present a major obstacle for treatment. Traditionally, insight has often been viewed as a simple or unitary construct. Recently, it is considered as a complex phenomenon with multiple components. A general lack of insight is widespread and very common in many patients with schizophrenia. Psycho-education is a form of mental health intervention which focuses on educating patients about their disorders, emotional responses, and treatments, as well as supporting positive coping mechanisms. The main purpose of this study was to determine the impact of psycho-education intervention on insight development among hospitalized schizophrenic patients. A structured frame of psycho-education intervention was developed by the researchers. The intervention aimed at increasing patients' awareness about their mental disorder, their symptoms as well as its attribution, the social consequences of mental disorder and the achieved effects of medication. Before the implementation of psycho-education intervention, the total Scale to Assess Unawareness of Mental Disorder (SUMD) mean scores for current awareness and attribution were 13.78 \pm 2.95 for the intervention group and $15.04 \pm 2.73$ for the control group (mild to moderate degree lack of insight). These results changed after the implementation of the psycho-education intervention to $7.96 \pm 2.81$ and $15.67 \pm 2.39$ respectively, with a statistical significant improvement $(\mathrm{t}=14.731, \mathrm{P}=0.00)$ on the part of the intervention group. This was also true when comparing the two groups' SUMD subscale mean scores.
\end{abstract}

\section{INTRODUCTION}

\section{Schizophrenia is a major psychiatric} disorder in which individuals experience a constellation of symptoms that include perceptual misinterpretation, cognitive impairment, and emotional dysfunction. These symptoms are commonly divided into the positive and negative symptoms, two distinct, yet overlapping system
The positive symptoms of schizophrenia consist of the hallucinations, delusions, positive thought disorder, bizarre or disorganized behavior, and catatonic motor behavior. The negative symptoms include affective blunting, impoverished thinking and cognition, anhedonia, avolition-apathy, and attentional impairments ${ }^{(1-3)}$.

Psychiatric Nursing and Mental Health Department

Faculty of Nursing, Alexandria University 
Relative to persons with other patient's comprehension of the nature and

psychiatric disorders, persons with schizophrenia spectrum disorders often lack insight into the nature and severity of their disorder ${ }^{(4-7)}$.

Lack of insight is one of the major problems confronting those who are caring for the mentally ill, lower levels of insight are believed to be associated with longer intervals between the onset of symptoms and the seeking of treatment, increased exacerbation of illness, non-adherence to treatment, greater number and longer duration of hospitalizations, and worse outcome ${ }^{(8-10)}$.

Like many other concepts, terminological confusion exists, with psychiatric textbooks describing insight as "the ability to recognize that one has a mental illness or is experiencing psychopathological symptoms"(11). In ordinary usage, insight is defined as the capacity to discern the true nature of a situation $^{(12)}$. It is a term typically used by mental health professionals to describe a causes of his or her problems ${ }^{(13,14)}$.

Traditionally, insight has often been viewed as a simple or unitary construct in which patients were classified as having either "good" or "poor" insight ${ }^{(15)}$. However, recent studies suggest that insight is a complex phenomenon with multiple components. The current definition of insight describes it as "a multidimensional concept that includes: awareness of mental disorder, awareness of the need for treatment, understanding of the social consequences of disorder, awareness of specific signs and symptoms of disorder, and attribution of symptoms to disorder, which in turn have current as well as retrospective aspects"(16,17). These insight dimensions are to some extent conceptually interrelated, they are not overlapping, they are dimensional and dynamic phenomena, which allow for particular variations along the course of the illness ${ }^{(4,18,19)}$.

Studies have demonstrated a positive 
effect of psycho-education intervention on the development of insight in schizophrenic patients. Evidence from trials suggests that psycho-educational approaches are useful as a part of the treatment program for people with schizophrenia. These approaches increase patient's understanding of his illness and its treatment ${ }^{(20,21)}$.

Psycho-education is a form of mental health intervention in which basic coping skills for dealing with various stressors are taught. It focuses on educating patients about their disorders, emotional responses and treatments, as well as supporting positive coping mechanisms. In this sense, it serves the goals of both treatment and rehabilitation and as such it is limited and also cost effective ${ }^{(22,23)}$.

Psycho-educational intervention can be delivered by a variety of health care professionals including psychiatric nurses ${ }^{(22)}$. Many writers agree that nurses should play a major role in patient education. However, due to the 24-hours contact the nurses have with hospitalized patients; nurses are seen as having the potential to be the main mediators of patient education and information giving. By providing continuous care, nurses are in a better position to assess the patients educational needs and readiness to learn ${ }^{(24,25)}$.

Insight is thought to be associated with good mental health and high quality of life. It is often an important therapeutic goal. A recent research suggests that insightful patients with schizophrenia have a better outcome. Insight often helps patients take an active role in managing their problems. Patients who achieve insight in the early stages of the disorder are more likely to accept treatment ${ }^{(26)}$. Accordingly, it is important to investigate ways to raise the level of insight in these patients. Therefore, the choice of psycho-education intervention to develop insight of schizophrenic patients can be very important.

\section{AIM OF THE STUDY}

Determine the impact of a psycho- 
education intervention on insight of hospitalized schizophrenic patients.

\section{MATERIAL AND METHODS}

Study design: the design of this study is quasi-experimental.

Setting: the study was conducted at ElMaamoura Hospital for Psychiatric Medicine in Alexandria. The hospital serves psychotic and drug dependent patients and is affiliated to the Ministry of Health and Population.

\section{Subjects:}

The subjects of this study comprised 100 hospitalized schizophrenic patients, 40 patients as an intervention group (4 females and 36 males) and 60 patients as a control group (6 females and 54 males). All patients met the following criteria:

1- Schizophrenic patients as diagnosed by medical staff, without inclusion of those having comorbidity.

2- Patients who have been sick for no more than five years.

3- Patients who passed the acute stage and are able to cooperate and respond in coherent and relevant manner.

4- Patients having mild to moderate lack of insight, as measured by the Scale to Assess Unawareness of Mental Disorder (SUMD) ${ }^{(15)}$.

All patients who were available at the time of data collection and who met the inclusion criteria were included in the study until the assigned number (100 pts) was completed.

Tools:

Two tools were used to collect the study data, they were:

Tool I- Socio-demographic and clinical data structured interview

This tool was developed by the researchers to elicit information related to:

a) Socio-demographic characteristics of patients (7 questions namely: sex, religion, age, place of residence, marital status, education, and occupation).

b) Clinical data (13 questions namely; duration of illness, age of patient at first attack, number of psychiatric hospitalizations, life-time psychiatric 
hospitalization, ...)

c) The sheet also included questions regarding coping with stress, stigma, patient's perception of others' reaction since he became ill, and his educational needs about illness.

\section{Tool II- A Scale to Assess} Unawareness of Mental Disorder (SUMD)

SUMD has been developed by Amador et al., (1993) $)^{(15)}$. It is a standardized scale on which ratings are made based on direct patient interview to assess current and past awareness of mental illness. The scale attempts to measure specific and global aspects of awareness and also assesses patients' attributions about the cause of different signs and symptoms. It represents a comprehensive and detailed approach that assesses several dimensions of patients' insight about their illness, the scale is composed of 20 items which are:

- Three general items (first, second, and third dimensions of insight) that include: awareness of having mental disorder (item 1 ), awareness of the achieved effects of medication (item 2), and awareness of the social consequences of mental disorder (item 3).

- Two subscale items (fourth and fifth dimensions of insight) consisting of: awareness of specific signs and symptoms (items $4 a-20 a)$ and attribution of specific signs and symptoms (items 4b-20b). Awareness relates to the recognition of the sign or symptoms of illness, while attribution refers to explanations as to the cause or source of theses signs and symptoms.

Rating for the general items was as follows: $0=$ can not be assessed or item not relevant, 1=complete awareness, 2=aware, 3=somewhat aware, 4=unaware, and $5=$ completely unaware.

This rating was applied also on assessing awareness of symptomatology. For each symptom-item on the scale, it must first be ascertained that the subject has exhibited the particular symptom during the period under investigation. The severity of the symptom is not relevant, 
only that it is clearly present. The symptom checklist must be completed prior to filling out the scale in order to determine which symptom items are relevant. The three non-symptom items 1, 2, and 3 (awareness of having mental disorder, awareness of the achieved effects of medication, and awareness of the social consequences of mental disorder) are usually relevant and should be completed if this is the case ${ }^{(15)}$.

Following each symptom item (\# 4-20), subject's understanding of the cause of the symptom (i.e., attribution) was rated only if the subject obtained a score between 1 and 3 on the awareness item. Rating attribution was as follows: $0=$ can not be assessed or item not relevant, 1=correct attribution, 2=not fully correct attribution, 3=partial attribution, 4=distorted attribution, and $5=$ incorrect attribution.

The assessment of both awareness of symptoms and attributions was done for the current as well as the past experiences. In the current column (C), the highest level of awareness obtained at the time of the interview for a specific psychopathology was rated. In the past column $(\mathrm{P})$, the level of awareness for each item occurring during the period of time preceding the current period of investigation was rated.

The score for each of the first three dimensions of SUMD (awareness of having mental disorder, awareness of the achieved effects of medication, and awareness of the social consequences of mental disorder) ranges from 1 to 5 . Subscale total score is obtained by summing up the completed items $4 a-20 a$ divided by the number of items completed for awareness items. Then by summing up the completed items $4 b-20 b$ divided by the number of items completed for attribution items. Therefore, the potential ranges are 1 to 5 for the two subscale items. The total SUMD score is calculated by summing up the ratings of the five dimensions. This can range from 5 to 25 in which score (5) reflects complete insight, score (15) denotes that the patient has moderate lack of insight, whereas score (25) refers to 
severe lack of insight.

This scale was applied on Egyptian psychiatric population by El-Maadawy (1997). It has been evaluated for validity and reliability on three different groups of patients of both sexes; Ain-Shams, Ahmed Maher, and Abbassya group. The scale was reported to be valid. As for its reliability, Interclass Correlation Coefficients (ICC) ranged from 0.69 to 0.99 (median=0.84), 0.52 to 0.99 (median=0.71), and 0.448 to 0.99 (median=0.64), respectively ${ }^{(27)}$.

\section{Methods}

A theoretical foundation and knowledge in psycho-education intervention and in group dynamics were developed by the researchers.

\section{Pilot study:}

A pilot study was carried out on a sample of five schizophrenic patients who had a duration of illness of no more than five years.

\section{The actual study:}

A survey of all hospital wards was done through reviewing all patients' charts in order to identify those who were meeting the inclusion criteria. The actual study was conducted in four phases:

\section{Phase I (selection of the subjects)}

A. The subjects were selected from free and private wards, starting with free female wards.

- Patients' records in one free female ward were surveyed to select the study subjects based on the recorded patients' history and diagnosis. The same process was followed in the rest of the female wards (one free and two private female wards).

- Survey of male wards was done during the period of implementing the study on female patients.

B. Patients' oral consent to participate in the study was obtained. Each selected patient was interviewed individually by the researchers. In the first 15 minutes of the interview, patients were encouraged to discuss their areas of concern, with a non-directive approach from the researchers, to establish rapport. 
After that, more specific information was the study. Patients' demographic obtained related to a range of positive and characteristics and clinical data were negative symptoms.

collected using the demographic and

SUMD was implemented on all selected clinical data sheet (tool I). This was done patients, their number amounted to 203 patients, using the interview method on an individual basis by the researchers to identify the severity of insight deficits among surveyed patients.

Phase II:

Results of SUMD were analyzed to identify patients with mild to moderate lack of insight. The range of possible values for the SUMD is 5 to 25 , with 5 being the greatest possible degree of insight. The mean insight score on the SUMD was 15 \pm 2.5 . Patients with mild to moderate degree lack of insight were selected (with a minimum score of 7.5 and a maximum score 22.5). So, patients having a score of 5 on SUMD (complete insight) and patients having score 25 on SUMD (severe lack of insight) were excluded. for each patient on an individual basis, in one or two consecutive sessions.

The researchers reviewed the medical records of full participants to collect information related to clinical variables, family history of mental illness, and patients' history as well as to ensure the accuracy of the obtained information from the patients, e.g., number of previous hospitalizations and the exact length of present hospitalization. Out of one hundred patients recruited; 60 patients were assigned to control group (not willing to participate in intervention) and the rest of patients who fulfilled the following criteria comprised the intervention group.

\section{Intervention group:}

Criteria for group inclusion:

The following criteria were considered

Patients identified as having mild to when recruiting the intervention group: moderate lack of insight were included in 1- Giving an informed oral consent to 
participate in the group.

2- Had controlled psychotic manifestations, mainly hallucinations and delusions.

3- Able to interact with other patients.

\section{Phase III:}

A structured frame of psycho-education intervention was developed by the researchers after a thorough review of literature ${ }^{(1,22,28-43)}$. The intervention aimed at increasing patients' awareness about their mental disorder, their symptoms, and their attribution of symptoms, the social consequences of mental disorder and the achieved effects of medication.

This psycho-education program was composed of eight topics about schizophrenia that were presented in a simplified Arabic language. These are:

- Introduction, definition, etiology of schizophrenia [Biological causes (neurotransmitters theory) and psychological causes (intra-personal factor, stress vulnerability)], and age of onset.
- Symptoms of the disease, both positive and negative.

- Phases of the illness (prodromal, active, stabilizing, and residual phases).

- Antipsychotic medications both typical and atypical (indication, mode of administration, mechanism of action, side effects, complications, management of side effects and complications) as well as the importance of treatment compliance inside and outside the hospital.

- Coping with stress.

i. Cognitive and behavioral adaptive coping techniques.

ii. Support system.

iii. Coping with hallucinations and delusions.

- Social consequences of the illness.

- Prognosis and relapse (warning signs, causes, and prevention of relapse).

- Stigma (definition, cultural believes about schizophrenia, sources of these believes, and facing the stigma).

Psycho-education intervention was implemented on a small group basis as 
follows:

1. The total number of the study subjects (40 patients) was divided into 8 subgroups. Each subgroup comprised 4-6 patients. Two to three groups were run by the researchers at the same time. Each group was homogenous in terms of sex.

2. Techniques used in the intervention were:

- Group instruction through minilectures (10-15 minutes each).

- Group discussion

- Other strategies, as brainstorming, were used in some sessions as in "coping with stress" and "stigma" sessions.

3. The intervention covered 8 topics, one topic per session. Each session took an hour for each group, once a week for eight consecutive weeks. All groups followed the same sequence of topics.

- After each session, the researchers wrote what happened in that session by the patients as well as a summary of the common themes tackled during it.

- Patients from the control group were left to undergo the usual hospital routine without any intervention from the researchers.

\section{Phase IV:}

Post assessment was done one week after the end of the last session for the intervention group, and the control group using SUMD (tool II) to evaluate the effectiveness of the psycho-education intervention on insight improvement.

Statistical Analysis:

After data collection, data were tabulated; coded and introduced to SPSS software version 11.5. Qualitative variables were described in frequencies and percentages, quantitative variables were described by mean and standard deviation. All statistical tests were conducted at $5 \%$ level of significance; variables were analyzed using chi-square test, Fisher's exact test, $\mathbf{Z}$ test, and t-test. 


\section{RESULTS}

Table (1) reveals that the majority of patients in the intervention and control groups were equally represented among male patients (90\% males each) and Moslems (97.5\% and 95\%, respectively). No statistical significant differences were found between the two groups in both cases $(\mathrm{P}=1.00$ and 0.648 respectively).

Concerning place of residence, more than half of the intervention group (57.5\%) and nearly three-quarters of the control group (71.7\%) were living in urban areas.

Regarding age, the mean age of both groups was around 27 years with age ranging between 15 and 45 years. No statistically significant differences were found between intervention and control groups regarding place of residence and age $\left(\chi^{2}=2.146\right.$ and 1.318, $P=0.143$ and 0.517 , respectively).

Concerning marital status, the majority of patients in the intervention and control groups $(87.5 \%$ and $75 \%$, respectively) were singles, while $7.5 \%$ and $6.7 \%$, respectively were married. No statistically significant difference was found between both groups $(P=0.150)$.

As regards education, it was found that the majority of the intervention group was equally distributed between the different levels of education, namely; illiterate and read and write, primary and preparatory education, and technical and secondary education (27.5\% each). The rest of the group (17.5\%) had either associate degree or university education. Comparatively, nearly two-thirds of the control group (33.3\% and $31.7 \%$, respectively) were in the illiterate and read and write group or in the primary and preparatory education group. No statistically significant difference was found between the two groups in this respect, $\left(\chi^{2}=1.152, \mathrm{P}=0.764\right)$.

In relation to patients' occupation, it was noted that about two-thirds of both groups were either employed until onset of the illness, or still working $(32.5 \%$ and $35 \%$ respectively of the intervention group, and $26.7 \%$ and $45 \%$ respectively of the control 
group), while the percentage of those unemployed among the intervention and control groups were $20 \%$ and $21.7 \%$, respectively with no statistically significant difference between the two groups $(\mathrm{P}=0.599)$.

Table (2) illustrates the clinical data of the intervention and control groups. It was found that the majority of the intervention and control groups (75\% and $88.3 \%$, respectively) were occupants of free wards. Concerning the duration of illness, it ranged between less than 2 years to 5 years with a mean of $3.67 \pm 1.41$ for the intervention group and $3.89 \pm 1.61$ for the control group. The majority of the intervention and control groups (87.5\% and $86.7 \%$, respectively) had a duration of illness ranging between 2 and 5 years. No statistically significant difference was found between both groups $\left(\chi^{2}=3.024\right.$ and 0.015 , $\mathrm{P}=0.082$ and 0.903 , respectively).

Concerning the age of patients at first attack, it was found that about two thirds of the intervention and control groups $(60 \%$ and $63.3 \%$, respectively) had their first attack at an age ranging between less than 15 years to less than 25 years with a mean age of $24.29 \pm 5.60$ and $23.86 \pm 6.24$, respectively for the intervention and control groups. As for the number of psychiatric hospitalizations, the majority of the intervention and control groups $(72.5 \%$ and $66.7 \%$, respectively) has been hospitalized from 1 to less than 5 times, while $22.5 \%$ and $26.7 \%$, respectively were hospitalized from 5 to less than 10 times. However, no statistically significant difference was found between intervention and control groups ( $P=0.948$ and 0.928 , respectively).

As for the life time psychiatric hospitalizations, a mean of $9.25 \pm 11.49$ and 8.62 \pm 12.19 months were recorded, respectively for both the intervention and control groups. The majority of the studied patients in the intervention and control groups (80\% and $78.3 \%$, respectively) were hospitalized from less than one month to less than 12 months. In relation to time lapse since first hospital admission it 
was noted that the intervention and control groups had a mean of $38.20 \pm 21.25$ and $39.12 \pm 21.48$ months, respectively. The table also shows that, $40 \%$ of the intervention group and $43.3 \%$ of the control group had a time lapse of 48 to 60 months since their first hospital admission, while $20 \%$ and $15 \%$ of the intervention and control groups, respectively didn't remember the date of their first admission. Regarding duration of current hospitalization, a mean of $2.21 \pm 2.54$ and $1.28 \pm 1.74$ months were recorded for both the intervention and control groups, respectively. The majority of the studied patients $(80 \%$ of the intervention group and $90 \%$ of the control group) were hospitalized for less than one month, and up to less than 3 months. In all cases, no statistically significant differences were found between the intervention and control groups $(P=1.00,0.880$, and 0.238 , respectively).

Regarding educational needs of the studied patients, table (3) reflects that definition of schizophrenia; its causes; medication; how to cope with stressors and how to deal with hallucinations and delusions were the most frequently expressed educational needs as mentioned by almost half of the subjects' sample. The percentage of those who wanted to know about the course and prognosis were $40 \%$ and $23.3 \%$ respectively for the intervention and control groups.

Table (4) reveals the mean scores of the Scale to Assess Unawareness of Mental Disorder (SUMD) among the intervention and control groups before implementing psycho-education intervention for past awareness and attribution. As regards SUMD total score, it was noted that the intervention group had a total mean score significantly lower compared to control group (15.34 \pm 2.66 ; 17.85 $\pm 2.60, \quad$ respectively $), \quad(\mathrm{t}=4.699$, $P=0.00$ ), i.e., the intervention group was more insightful than the control group. Concerning the five SUMD subscale items, the table shows the same pattern in the 
mean scores of awareness of having found that there was no variation in the mental disorder, awareness of social mean scores of awareness of having consequences of mental disorder, mental disorder, awareness of the awareness of specific signs and symptoms, achieved effects of medication, and and attribution of specific signs and attribution of specific signs and symptoms. symptoms. Accordingly, t-test showed a Accordingly, t-test showed no statistical statistical significant difference between the significant difference regarding those intervention and control group regarding dimensions $(t=0.702,0.141$, and 1.627; those dimensions ( $t=3.269,2.485,2.371, \quad P=0.484,0.888$ and 0.107 , respectively). and 2.192; $P=0.002,0.015,0.020$ and $O n$ the other hand, significant variations 0.031 , respectively).

Table (5) shows the mean scores of SUMD among the intervention and control groups before implementing psychoeducation intervention for current awareness and attribution. It can be seen that, the intervention and control groups were found in the areas of awareness of social consequences of mental disorder and awareness of specific signs and symptoms $(\mathrm{t}=2.266$ and $2.593 ; \mathrm{P}=0.026$ and 0.011 , respectively).

After implementing the psychoeducation intervention, table (6) shows that had a total mean score of $13.78 \pm 2.95$, the intervention group had an obvious whereas the control group had a total increase in their level of insight with a total mean score of $15.04 \pm 2.73$. A statistical mean score of $7.96 \pm 2.81$. Concerning the significant difference was detected SUMD subscale items (awareness of between the intervention and control having mental disorder, awareness of the groups ( $\mathrm{t}=2.199, \mathrm{P}=0.030$ ). As for SUMD achieved effects of medication, awareness subscale items (five dimensions) among of social consequences of mental disorder, the intervention and control groups, it was awareness of specific signs and symptoms, 
and attribution of specific signs and symptoms respectively), their mean scores were $1.68 \pm 1.14, \quad 1.65 \pm 0.95, \quad 1.30 \pm 0.91$, $1.38 \pm 0.46$, and $1.96 \pm 0.81$, respectively (a much less value than those reported before the program). On the other hand, the control group still had nearly the same level of lack of insight as compared to their current awareness and attribution before implementing the psycho-education intervention. The mean of SUMD total score was $15.67 \pm 2.39$. As well, the SUMD subscale items (five dimensions) were still as high as before. A statistical significant difference was noted between the intervention and control groups regarding SUMD total score $(t=14.731, P=0.00)$, as well as SUMD subscale items (awareness of having mental disorder, awareness of the achieved effects of medication, awareness of social consequences of mental disorder, awareness of specific signs and symptoms, and attribution of specific signs and symptoms) with $t=9.115$, $5.709,5.733,6.125$, and 16.397 , on the total score, it was observed that respectively; $P=0.00$ in all items.

Table (7) illustrates the effect of psycho-education intervention on the total score of the intervention and control groups. Regarding the main effect of time on the total score of the total sample, the table shows that there is a significant main effect of time factor on the total score, with $F(2,196)=129.39, \quad P<0.05 . \quad$ Further contrasts revealed that the total current score is significantly lower than the total past score with $F(1,98)=53.68, P<0.000$, while the total post-education score is significantly lower than the total current score with $F(1,98)=91.86, P<0.000$.

As for the effect of psycho-education intervention on the total insight score, the table shows that the study subjects scored significantly less than controls $(12.36 \pm 0.328,16.19 \pm 0.268$, respectively) on their total means with $F(1,98)=81.77$, $\mathrm{P}<0.000$.

Concerning the interaction effect of time factor and psycho-education intervention on the total score, it was observed that 
there was a significant intervention effect between the change in the total score over time and whether the patient was subjected to psycho-education or not, with $F(2,196)=66.176, P<0.000$. This indicates that the change in the total score is different in intervention and control groups. To break down this interaction, contrasts were performed and revealed that:

- There was a significant interaction at the first level (change from the past to current situations), $\quad F(1,98)=4.0406$, $\mathrm{P}<0.05$.

- There was a significant interaction at the second level (change from current to post-education situations), $F(1,98)=141.93$, $\mathrm{P}<0.000$.

\section{DISCUSSION}

Many psychotic patients, specifically schizophrenics, display a lack of insight into their disorder. These patients appear to deny, fail to acknowledge, or more broadly, lack awareness of having a mental disorder or symptoms of a mental disorder ${ }^{(15)}$. The attitude of the patient towards his illness has obvious clinical implications $^{(13,44)}$. Poor insight may play an important role in the course and treatment of schizophrenic patients. It has considerable power in predicting the longterm course of chronic mental disorders and an impact on patient's compliance with treatment plans ${ }^{(8,15,45,46)}$.

Many studies revealed that patients do not have enough information about their disorder, medications and other therapies and they are non-compliant with therapy ${ }^{(47-}$ 49). This was also proved in the present study as almost half of the subjects expressed their need to know about schizophrenia, its causes, medications, ways of coping with stressors, and ways of dealing with hallucinations and delusions. This pertinent lack of knowledge among the present schizophrenic Egyptian subjects, can be partly due to general belief of some of the health professionals (as observed by the researchers), that schizophrenic patients have great difficulty understanding or retaining new concepts. 
Even if the individual can understand what is being taught, it is widely believed that mentally ill persons fail when trying to generalize new skills to other settings or change dysfunctional patterns of coping.

The results of the present study revealed a statistically significant positive effect of the carried out psycho-educational program on the total scores (past, current, and post) of the Scale to Assess Unawareness of Mental Disorder (SUMD). The intervention group became significantly more insightful than the control group. This is also true when comparing the two groups total scale and subscale mean scores (awareness of having mental disorder, awareness of the achieved effects of medications, awareness of the social consequences of mental disorder, awareness of specific signs and symptoms, and attribution of specific signs and symptoms) after implementing the psychoeducational program. Such a result is supported by researcher evidences which indicate that people with schizophrenia are able to learn and understand information relevant to their condition ${ }^{(50)}$.

Actually, the significant improvement in the level of insight among the intervention group in the present study from current to post-education intervention can be due to the positive impact of the interaction effect of time factor and psycho-education intervention, as well as the positive impact of the nurse-patient (researcher-patient) relationship. This was evident when looking at the great improvement in the intervention group level of insight at the post-education assessment, as compared to the modest insight improvement in the control group. Needless to say that establishing a nurse-patient relationship helps both nurse and patient to work together towards specific changes in behavior $^{(24)}$. It is thought that a positive trusting relationship that the researcher developed with patients increased the effectiveness of the education. Dogan and Sabanciogullari (2003) stressed that just providing information is not sufficient in 
patients' compliance to treatment and that it is necessary to have a wider scope for the relationship and interaction with patients $^{(51)}$. In the present study, the good attendance rates reflected patients' willingness to attend, their interest in the psycho-education provided, and their degree of trust in the researcher, other patients and the group structure as a whole. The attendance rates also indicated that the psycho-education group was succeeding in meeting some of the clients' needs. The most rewarding measures indicating that learning has occurred were evident from excellent group attendance, discussions that easily filled the group time (and sometimes beyond), and direct feedback from group members (e.g., when a member comes up to the researcher and states "I learned two things from the session, about... and ...") indicating that the psycho-education intervention was considered to be a useful program for increasing schizophrenic patients' level of insight.
Consistent with the results of the present study, several other studies have demonstrated a positive effect for psychoeducation on the development of insight into psychotic illness ${ }^{(52-54)}$. Consistently, Macpherson et al (1996) found that preintervention low levels of knowledge about illness and treatment increased significantly immediately after a standard education session, and was accompanied in schizophrenic patients with significantly increased insight into illness ${ }^{(55)}$. Other researchers reported that educational interventions were effective in improving patients' knowledge about the disorder and

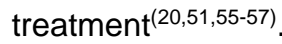

Accordingly, insight is not an end in itself but one way to improve schizophrenic patient's ability to understand his illness and the advantages and disadvantages of treatment, and to enhance the quality of his life. This fact underscores the importance of developing reliable, cost-effective ways to enhance awareness of illness in these patients ${ }^{(26,52)}$. Educating patients about the 
disorder and medication has an effect on enhancing schizophrenic patients' level of insight, as well as their cognitive and emotional well-being ${ }^{(12,58)}$. The implication of this intervention in the field of psychiatric nursing is enormous, because it appears that it adds meaning to patients' life. The respectful and empowering approach, and the close and trusting relationship with the nurse found in this intervention, could be as curative as the type of psychotropic medications the patient takes. Psychoeducation intervention is an important and necessary aspect of health care. It is one of the important nursing roles that must be well planned to provide relevant nursing care for schizophrenic patients.

\section{CONCLUSION AND RECOMMENDATIONS}

According to the findings of the present study, it can be concluded that psychoeducation intervention can bring a significant improvement in the schizophrenic patients' level of insight. Psycho-education intervention is effective in improving various insight dimensions namely, awareness of having mental disorder, awareness of the achieved effects of medication, awareness of social consequences of mental disorder, awareness of specific signs and symptoms, and attribution of specific signs and symptoms. Such intervention can and should be used in the field of psychiatric nursing.

In the light of the results of this study, the following recommendations are suggested:

1- The use of a reliable, systematic assessment tool to measure the degree and quality of unawareness in schizophrenic patients is a need. This can be incorporated in the initial and ongoing assessments of patients in treatment settings.

2- Sustained psycho-educational approaches that aim at improving illness awareness are recommended and must deserve a prominent place in care programs of schizophrenic patients.

3- Similar psycho-education program may be expanded and extended to include schizophrenic patient's family. This may render family members more helpful and supportive to the development of insight in their patients. 
4- Nurses can be trained to be more initiative, assume responsibility, and be confident to take on the educator role and assist schizophrenic patients in developing an understanding of their illness.

5- Additional research is needed to investigate patient's retention of knowledge - and hence insight - over longer periods of time.

Table 1: Socio-demographic characteristics of the patients in the intervention and control groups

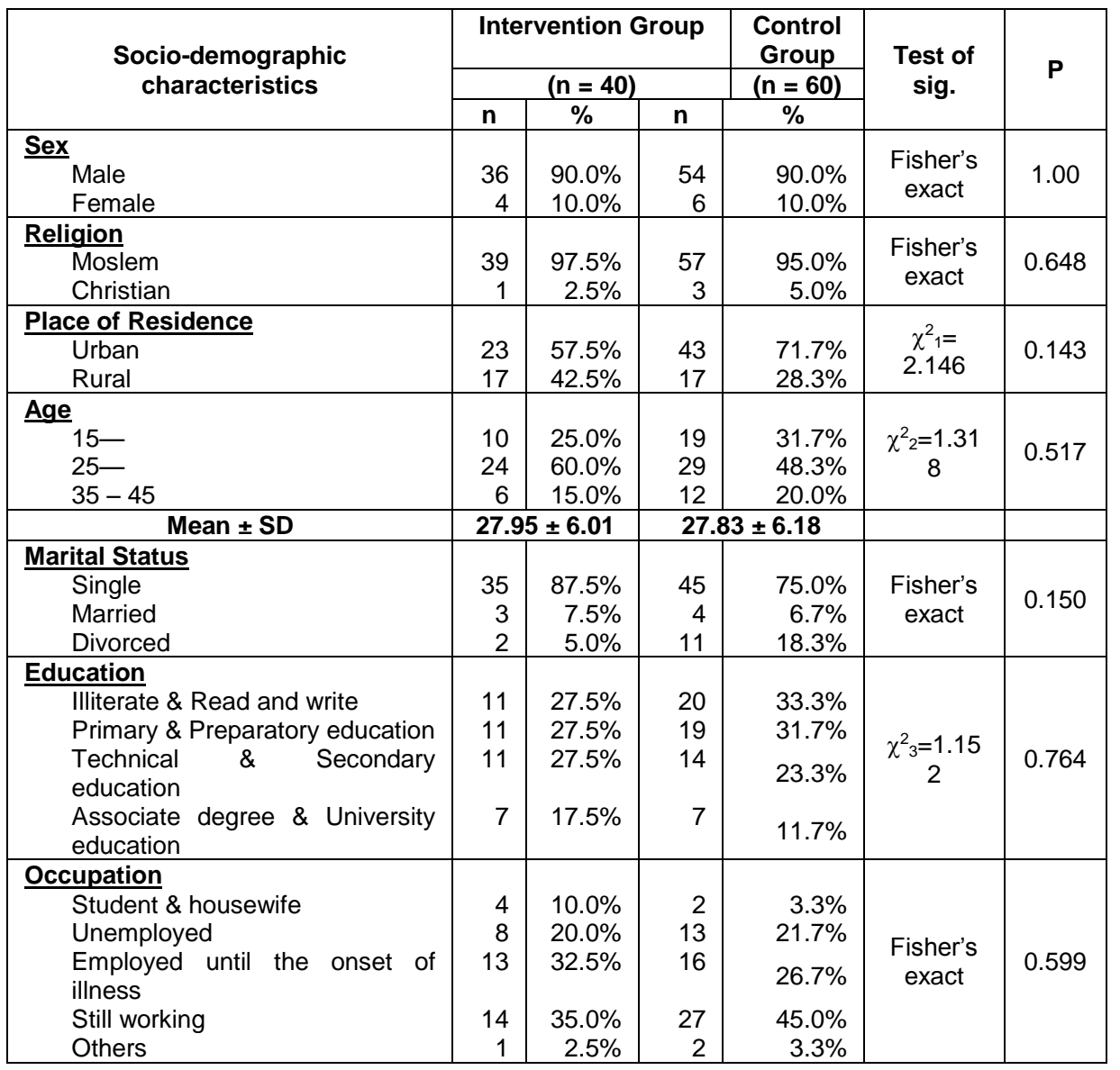


Table 2: Clinical data of patients in the intervention and control groups

\begin{tabular}{|c|c|c|c|c|c|c|}
\hline \multirow[t]{2}{*}{ Clinical data } & \multirow{2}{*}{\multicolumn{2}{|c|}{$\begin{array}{c}\text { Intervention } \\
\text { Group } \\
(\mathbf{n}=\mathbf{4 0})\end{array}$}} & \multirow{2}{*}{\multicolumn{2}{|c|}{$\begin{array}{c}\text { Control } \\
\text { Group } \\
(n=60)\end{array}$}} & \multirow{2}{*}{$\begin{array}{l}\text { Test of } \\
\text { sig. }\end{array}$} & \multirow[t]{2}{*}{$\mathbf{P}$} \\
\hline & & & & & & \\
\hline $\begin{array}{l}\text { Ward } \\
\text { Private } \\
\text { Free }\end{array}$ & $\begin{array}{l}10 \\
30\end{array}$ & $\begin{array}{l}25.0 \% \\
75.0 \%\end{array}$ & $\begin{array}{r}7 \\
53\end{array}$ & $\begin{array}{l}11.7 \% \\
88.3 \%\end{array}$ & $\begin{array}{c}\chi^{2}{ }_{1}= \\
3.024\end{array}$ & 0.082 \\
\hline $\begin{array}{c}\text { Duration of illness } \\
<2 \text { years } \\
2-5 \text { years }\end{array}$ & $\begin{array}{r}5 \\
35\end{array}$ & $\begin{array}{l}12.5 \% \\
87.5 \%\end{array}$ & $\begin{array}{r}8 \\
52\end{array}$ & $\begin{array}{l}63.3 \% \\
86.7 \%\end{array}$ & $\chi^{2}{ }_{2}=0.015$ & 0.903 \\
\hline $\begin{array}{l}\text { Mean } \pm \text { SD } \\
\text { Age at first attack (years) } \\
<25 \\
25- \\
35-45\end{array}$ & $\begin{array}{r}24 \\
13 \\
3 \\
\end{array}$ & $\begin{array}{r}60.0 \% \\
32.5 \% \\
7.5 \% \\
\end{array}$ & $\begin{array}{r}38 \\
18 \\
4 \\
\end{array}$ & $\begin{array}{r}63.3 \% \\
30.0 \% \\
6.7 \% \\
\end{array}$ & $\begin{array}{c}\text { Fisher's } \\
\text { exact }\end{array}$ & 0.948 \\
\hline Mean \pm SD & \multicolumn{2}{|c|}{$24.29 \pm 5.60$} & \multicolumn{2}{|c|}{$23.86 \pm 6.24$} & & \\
\hline $\begin{array}{l}\text { Number of } \\
\frac{\text { hospitalizations }}{1-} \\
5- \\
10- \\
15- \\
20-25\end{array}$ & $\begin{array}{r}29 \\
9 \\
2 \\
0 \\
0\end{array}$ & $\begin{array}{r}72.5 \% \\
22.5 \% \\
5.0 \% \\
0.0 \% \\
0.0 \%\end{array}$ & $\begin{array}{r}40 \\
16 \\
3 \\
0 \\
1\end{array}$ & $\begin{array}{r}66.7 \% \\
26.7 \% \\
5.0 \% \\
0.0 \% \\
1.6 \%\end{array}$ & $\begin{array}{c}\text { Fisher's } \\
\text { exact }\end{array}$ & 0.928 \\
\hline Mean \pm SD & \multicolumn{2}{|c|}{$3.78 \pm 2.75$} & \multicolumn{2}{|c|}{$4.03 \pm 3.36$} & & \\
\hline $\begin{array}{l}\text { Life-time psychiatric hospitalizations } \\
\text { (months) } \\
<12 \\
12- \\
24- \\
36- \\
48-60\end{array}$ & $\begin{array}{r}32 \\
5 \\
1 \\
1 \\
1\end{array}$ & $\begin{array}{r}80.0 \% \\
12.5 \% \\
2.5 \% \\
2.5 \% \\
2.5 \% \\
\end{array}$ & $\begin{array}{r}47 \\
7 \\
3 \\
1 \\
2\end{array}$ & $\begin{array}{r}78.3 \% \\
11.7 \% \\
5.0 \% \\
1.7 \% \\
3.3 \% \\
\end{array}$ & $\begin{array}{c}\text { Fisher's } \\
\text { exact }\end{array}$ & 1.00 \\
\hline Mean \pm SD & \multicolumn{2}{|c|}{$9.25 \pm 11.49$} & \multicolumn{2}{|c|}{$8.62 \pm 12.19$} & & \\
\hline $\begin{array}{lll}\text { Time lapse since } & \mathbf{1}^{\text {st }} & \text { hospital } \\
\text { admission (months) } & & \\
\text { Didn't remember } & & \\
<12 & \\
12- & & \\
24- & \\
36- & & \\
48-60 & & \\
\end{array}$ & $\begin{array}{r}8 \\
6 \\
2 \\
3 \\
5 \\
16\end{array}$ & $\begin{array}{r}20.0 \% \\
15.0 \% \\
5.0 \% \\
7.5 \% \\
12.5 \% \\
40.0 \% \\
\end{array}$ & $\begin{array}{r}9 \\
8 \\
7 \\
4 \\
6 \\
26\end{array}$ & $\begin{array}{r}15.0 \% \\
13.3 \% \\
11.7 \% \\
6.7 \% \\
10.0 \% \\
43.3 \% \\
\end{array}$ & $\begin{array}{c}\text { Fisher's } \\
\text { exact }\end{array}$ & 0.880 \\
\hline Mean \pm SD & & $\begin{array}{l}20 \pm \\
.25\end{array}$ & & 21.48 & & \\
\hline $\begin{array}{l}\text { Duration of current hospitalization } \\
\text { (months) } \\
\quad<3 \\
3- \\
6- \\
9-12\end{array}$ & $\begin{array}{r}32 \\
4 \\
2 \\
2\end{array}$ & $\begin{array}{r}80.0 \% \\
10.0 \% \\
5.0 \% \\
5.0 \%\end{array}$ & $\begin{array}{r}54 \\
5 \\
0 \\
1\end{array}$ & $\begin{array}{r}90.0 \% \\
8.3 \% \\
0.0 \% \\
1.7 \%\end{array}$ & $\begin{array}{c}\text { Fisher's } \\
\text { exact }\end{array}$ & 0.238 \\
\hline Mean \pm SD & 2.2 & \pm 2.54 & & 1.74 & & \\
\hline
\end{tabular}


Table 3: Educational needs of patients in the intervention and control groups

\begin{tabular}{|c|c|c|c|c|}
\hline \multirow[t]{2}{*}{ Knowledge required about illness ${ }^{*}$} & \multicolumn{2}{|c|}{$\begin{array}{c}\text { Intervention } \\
\text { Group } \\
(n=40) \\
\end{array}$} & \multicolumn{2}{|c|}{$\begin{array}{c}\begin{array}{c}\text { Control } \\
\text { Group }\end{array} \\
(n=60)\end{array}$} \\
\hline & $\mathbf{n}$ & $\%$ & $\mathbf{n}$ & $\%$ \\
\hline Definition & 22 & $55.0 \%$ & 36 & $60.0 \%$ \\
\hline Causes & 19 & $47.5 \%$ & 24 & $40.0 \%$ \\
\hline Symptoms & 7 & $17.5 \%$ & 12 & $20.0 \%$ \\
\hline Stages & 6 & $15.0 \%$ & 13 & $21.7 \%$ \\
\hline Medication & 23 & $57.5 \%$ & 34 & $56.7 \%$ \\
\hline $\begin{array}{l}\text { How to cope with stress and how to deal with } \\
\text { hallucinations \& delusions }\end{array}$ & 20 & $50.0 \%$ & 24 & $40.0 \%$ \\
\hline Social consequences of the illness & 3 & $7.5 \%$ & 9 & $15.0 \%$ \\
\hline Course and prognosis & 16 & $40.0 \%$ & 14 & $23.3 \%$ \\
\hline Stigma & 7 & $17.5 \%$ & 11 & $18.3 \%$ \\
\hline Causes of relapse & 4 & $10.0 \%$ & 9 & $15.0 \%$ \\
\hline Nothing & 1 & $2.5 \%$ & 7 & $11.7 \%$ \\
\hline Others & 6 & $15.0 \%$ & 9 & $15.0 \%$ \\
\hline
\end{tabular}

${ }^{*}$ Responses are not mutually exclusive.

Table 4: Mean scores of the intervention and control groups on SUMD before implementing the psycho-education intervention for past awareness and attribution.

\begin{tabular}{|c|c|c|c|c|}
\hline SUMD & $\begin{array}{c}\text { Intervention } \\
\text { Group } \\
(\mathbf{n}=40) \\
\text { Mean } \pm \text { SD } \\
\end{array}$ & $\begin{array}{c}\begin{array}{c}\text { Control } \\
\text { Group }\end{array} \\
(n=60) \\
\text { Mean } \pm \text { SD } \\
\end{array}$ & $\mathbf{t}$ & $\begin{array}{l}\text { (2-tailed) } \\
\text { (sig.) }\end{array}$ \\
\hline $\begin{array}{l}\text { Awareness of having mental } \\
\text { disorder }\end{array}$ & $3.35 \pm 1.58$ & $4.28 \pm 1.08$ & 3.269 & $0.002^{*}$ \\
\hline $\begin{array}{l}\text { Awareness of the achieved effects } \\
\text { of medication }\end{array}$ & $3.28 \pm 1.18$ & $3.58 \pm 1.21$ & 1.261 & $0.210^{*}$ \\
\hline $\begin{array}{l}\text { Awareness of social } \\
\text { consequences of mental disorder }\end{array}$ & $3.08 \pm 1.59$ & $3.83 \pm 1.43$ & 2.485 & $0.015^{*}$ \\
\hline $\begin{array}{l}\text { Awareness of specific signs and } \\
\text { symptoms }\end{array}$ & $1.69 \pm 0.45$ & $1.93 \pm 0.52$ & 2.371 & $0.020^{*}$ \\
\hline $\begin{array}{l}\text { Attribution of specific signs and } \\
\text { symptoms }\end{array}$ & $3.93 \pm 0.68$ & $4.22 \pm 0.77$ & 2.192 & $0.031^{*}$ \\
\hline Total score & $15.34 \pm 2.66$ & $17.85 \pm 2.60$ & 4.699 & $0.000^{*}$ \\
\hline
\end{tabular}

${ }^{*}$ Significant level at $p<0.05$ 
Table 5: Mean scores of SUMD among the intervention and control groups before implementing psycho-education intervention for current awareness and attribution.

\begin{tabular}{|c|c|c|c|c|}
\hline \multirow[t]{2}{*}{ SUMD } & $\begin{array}{c}\text { Intervention } \\
\text { Group } \\
(n=40) \\
\end{array}$ & $\begin{array}{c}\begin{array}{c}\text { Control } \\
\text { Group }\end{array} \\
(\mathrm{n}=60) \\
\end{array}$ & \multirow[t]{2}{*}{$\mathbf{t}$} & \multirow[t]{2}{*}{$\begin{array}{c}(2- \\
\text { tailed) } \\
\text { (sig.) }\end{array}$} \\
\hline & Mean \pm SD & Mean \pm SD & & \\
\hline $\begin{array}{l}\text { Awareness of having mental } \\
\text { disorder }\end{array}$ & $2.63 \pm 1.00$ & $2.75 \pm 0.77$ & 0.702 & 0.484 \\
\hline $\begin{array}{l}\text { Awareness of the achieved effects } \\
\text { of medication }\end{array}$ & $3.00 \pm 1.26$ & $2.97 \pm 0.99$ & 0.141 & 0.888 \\
\hline $\begin{array}{l}\text { Awareness of social consequences } \\
\text { of mental disorder }\end{array}$ & $2.28 \pm 1.34$ & $2.92 \pm 1.42$ & 2.266 & $0.026^{\star}$ \\
\hline $\begin{array}{l}\text { Awareness of specific signs and } \\
\text { symptoms }\end{array}$ & $1.87 \pm 0.50$ & $2.15 \pm 0.55$ & 2.593 & $0.011^{*}$ \\
\hline $\begin{array}{l}\text { Attribution of specific signs and } \\
\text { symptoms }\end{array}$ & $4.00 \pm 0.64$ & $4.24 \pm 0.74$ & 1.627 & 0.107 \\
\hline Total score & $13.78 \pm 2.95$ & $\begin{array}{c}15.04 \pm \\
2.73\end{array}$ & 2.199 & $0.030^{*}$ \\
\hline
\end{tabular}

* Significant level at $p<0.05$

Table 6: Mean scores of SUMD among the intervention and control groups after implementing psycho-education intervention.

\begin{tabular}{|c|c|c|c|c|}
\hline SUMD & $\begin{array}{c}\text { Intervention } \\
\text { Group } \\
(n=40) \\
\text { Mean } \pm \text { SD }\end{array}$ & $\begin{array}{c}\begin{array}{c}\text { Control } \\
\text { Group }\end{array} \\
(n=60) \\
\text { Mean } \pm \text { SD }\end{array}$ & $\mathbf{t}$ & $\begin{array}{c}(2- \\
\text { tailed) } \\
\text { (sig.) }\end{array}$ \\
\hline $\begin{array}{l}\text { Awareness of having mental } \\
\text { disorder }\end{array}$ & $1.68 \pm 1.14$ & $3.65 \pm 1.01$ & 9.115 & $0.000^{*}$ \\
\hline $\begin{array}{l}\text { Awareness of the achieved } \\
\text { effects of medication }\end{array}$ & $1.65 \pm 0.95$ & $2.95 \pm 1.21$ & 5.709 & $0.000^{*}$ \\
\hline $\begin{array}{l}\text { Awareness of social } \\
\text { consequences of mental disorder }\end{array}$ & $1.30 \pm 0.91$ & $2.63 \pm 1.41$ & 5.733 & $0.000^{*}$ \\
\hline $\begin{array}{l}\text { Awareness of specific signs and } \\
\text { symptoms }\end{array}$ & $1.38 \pm 0.46$ & $1.99 \pm 0.52$ & 6.125 & $0.000^{*}$ \\
\hline $\begin{array}{l}\text { Attribution of specific signs and } \\
\text { symptoms }\end{array}$ & $1.96 \pm 0.81$ & $4.45 \pm 0.70$ & 16.397 & $0.000^{*}$ \\
\hline Total score & $7.96 \pm 2.81$ & $15.67 \pm 2.39$ & 14.731 & $0.000^{*}$ \\
\hline
\end{tabular}

* Significant level at $p<0.05$ 
Table 7: the effect of psycho-education intervention on the total score of the intervention and control groups

\begin{tabular}{|c|c|c|c|c|c|}
\hline \multicolumn{2}{|c|}{$\begin{array}{l}\text { Medication } \\
\text { compliance }\end{array}$} & \multicolumn{2}{|c|}{ Mean \pm SD } & Effect F (sig.) & $\begin{array}{l}\text { Contrast F(sig.) } \\
\text { In comparison with } \\
\text { current total score }\end{array}$ \\
\hline \multicolumn{2}{|c|}{$\begin{array}{l}\text { Total Past } \\
\text { Total current } \\
\text { Total post }\end{array}$} & \multicolumn{2}{|c|}{$\begin{array}{l}16.85 \pm 2.89 \\
14.54 \pm 2.87 \\
12.59 \pm 4.57\end{array}$} & $\begin{array}{c}F(2,196)=129.39 \\
P=0.000^{*}\end{array}$ & $\begin{array}{l}F(1,98)=53.68, P=0.000^{*} \\
F(1,98)=91.86, P=0.000^{*}\end{array}$ \\
\hline \multicolumn{6}{|c|}{ The main effect of psycho-education on the total score (past, current and post) } \\
\hline \multicolumn{2}{|c|}{ Psycho-education } & Mean & S.E & \multicolumn{2}{|c|}{ Effect $F$ (sig.) } \\
\hline & $\begin{array}{l}\text { Intervention } \\
\text { Group } \\
\text { Control } \\
\text { Group } \\
\end{array}$ & $\begin{array}{l}12.36 \\
16.19\end{array}$ & $\begin{array}{l}0.328 \\
0.268\end{array}$ & \multicolumn{2}{|c|}{$F(1,98)=81.77, \quad P=0.000^{*}$} \\
\hline \multicolumn{6}{|c|}{ The interaction effect of time factor and psycho-education on the total score. } \\
\hline \multicolumn{2}{|c|}{ Total Score } & \multicolumn{2}{|c|}{ Mean \pm SD } & Effect F (sig.) & $\begin{array}{l}\text { Contrast F(sig.) } \\
\text { In comparison with } \\
\text { current total score }\end{array}$ \\
\hline $\begin{array}{l}\text { Total } \\
\text { past }\end{array}$ & $\begin{array}{l}\text { Intervention } \\
\text { Group } \\
\text { Control Group }\end{array}$ & \multicolumn{2}{|c|}{$\begin{array}{l}15.34 \pm 2.66 \\
17.85 \pm 2.60\end{array}$} & \multirow{3}{*}{$\begin{array}{c}F(2,196)=66.18 \\
P=0.000^{*}\end{array}$} & $F(1,98)=4.406, P=0.038^{*}$ \\
\hline $\begin{array}{l}\text { Total } \\
\text { current }\end{array}$ & $\begin{array}{l}\text { Intervention } \\
\text { Group } \\
\text { Control Group }\end{array}$ & \multicolumn{2}{|c|}{$\begin{array}{l}13.78 \pm 2.95 \\
15.04 \pm 2.73\end{array}$} & & \\
\hline $\begin{array}{l}\text { Total } \\
\text { post }\end{array}$ & $\begin{array}{l}\text { Intervention } \\
\text { Group } \\
\text { Control Group }\end{array}$ & \multicolumn{2}{|c|}{$\begin{array}{c}7.96 \pm 2.81 \\
15.67 \pm 2.39\end{array}$} & & $\begin{array}{c}F(1,98)=141.93 \\
P=0.000^{*}\end{array}$ \\
\hline
\end{tabular}

\section{REFERENCES}

1. Kay S, Fiszbein A, Opler L. The positive and negative syndrome scale (PANSS) for schizophrenia. Schizophr Bull. 1987; 13: 261-75.

2. Andreason N, Arndt S, Alliger R, Miller D, Flaum M. Symptoms of schizophrenia: methods, meanings and mechanism. Arch Gen Psychiatry. 1995; 52: 341-51.

3. Andreason N. Symptoms, signs and diagnosis of schizophrenia. Lancet. 1995; 346: 477-81.

4. Amador X, Strauss D, Yale S, Gorman J. Awareness of illness in schizophrenia. Schizophr Bull. (1991); 17(1): 113-32.

5. Amador X. I am not sick, I don't need help! In: Hasson-Ohayon I, Kravetz S,
Roe D, David A, Weiser M. Insight into psychosis and quality of life. Comprehensive Psychiatry. (2006); 47: 265-9.

6. Pini S, Cassano G, Dell'Osso L, Amador $X$. Insight into illness in schizophrenia, schizoaffective disorder, and mood disorders with psychotic features. Am J Psychiatry. (2001); 158: 122-5.

7. Amador $X$, Flaum $M$, Andreasen $N$, Strauss D, Yale S. Awareness of illness in schizophrenia and schizoaffective and mood disorders. Arch Gen Psychiatry, (1994); 51:826-36.

8. McGlynn S, Schacter D. The neuropsychology of insight: impaired awareness of deficits in a psychiatric context. Psychiatric Annals. (1997); 27(12): 806-11. 
9. Paulo S. Insight into schizophrenia: a comparative study between patients and family members. Med J (2004); 122(6): 246-51. Available from: http://www.alfesam.com

10. Amador $X$, David A. Insight and psychosis. Edited volume. UK: Oxford University Press, (1997).

11. Williams C, Collins A. Factors associated with insight among outpatients with serious mental illness. Psychiatr Serv. (2002); 53(1): 96-8.

12. Mintz A, Dobson K, Romney D. Insight in schizophrenia: a meta-analysis. Schizophr Res. (2003); 61: 75-88.

13. Goodman C, Knoll G, Isakov V, Silver H. Insight into illness in schizophrenia. Comprehene Psychiatry. (2005); 46: 284-90.

14. Kaplan H, Sadock B, Grebb J. Kaplan and Sadock's synopsis of psychiatry: behavioral sciences, clinical psychiatry. $7^{\text {th }}$ ed. Baltimore: Williams \& Wilkins Co. (1994).

15. Amador X, Strauss D, Yale S, Flaum M, Endicott J, Gorman J. Assessment of insight in psychosis. Am J psychiatry. (1993); 150(6): 873-9.

16. Amador $X$, Flaum $M$, Andreasen $N$, Strauss D, Yale S. Awareness of illness in schizophrenia and mood disorders. Arch Gen Psychiatry. (1995); 51:826-36.

17. Smith $T$, Hull J, Israel L, Wilson $D$. Insight, symptoms, and neurocognition in schizophrenia and schizoaffective disorder. Schizophr Bull. (2000); 26(1):193-200.

18. David A. Insight and psychosis. $\mathrm{Br} \mathrm{J}$ Psychiatry. (1990); 156: 798-808.

19. Markova M, Berrios B. Insight in clinical psychiatry: a new model. J Nerv Ment Dis. (1995); 184: 743-51.

20. Gray R, Wykes T, Gournay K. From compliance to concordance: a review of the literature on interventions to enhance compliance with antipsychotic medication. J Psychiatr Ment Health Nurs. (2002); 9: 277-84.

21. Pekkala E, Merinder L. Psychoeducation for schizophrenia (Cochrane Review). The Cochrane Library. (2001); 3: 1-2.
22. Boyd M, Nihart M. Psychiatric nursingcontemporary practice. Philadelphia: Lippincott Co; (1998).

23. Nightingale L, McQueen D. Group therapy for schizophrenia: combining and expanding the psycho-educational model with supportive psychotherapy. International Journal of Group Psychotherapy. (1996); 46(4): 517-33.

24. Holloway A. Patient knowledge and information concerning medication on discharge from hospital. J Adv Nurs. (1996); 24: 1169-74.

25. Syred M. The abdication of the role of health education by hospital nurses. J Adv Nurs. (1981); 6: 27-33.

26. McGorry $P$, McConville $S$. Insight in psychosis. Harvard Mental Health Letter. (2000); November. Available from:http://www.ps.psychiatryonline.org/c gi/content/full/2003

27. El-Maadawy T. Assessment of insight in a sample of Egyptian psychotic patients. Unpublished Master Thesis. Faculty of Medicine. Ain Shams University. (1997).

28. Meijel B, Gaag M, Kahn R, Grypdonck $M$. Recognition of early warning signs in patients with schizophrenia: a review of the literature. International Journal of Mental Health Nursing. (2004); 13: 10716.

29. Andreason N. The Scale for the Assessment of Negative Symptoms (SANS). lowa City, IA: The University of lowa; (1983).

30. Johnson B. Psychiatric mental health nursing: adaptation and growth. $4^{\text {th }}$ ed. Philadelphia: Lippincott Co; (1997).

31. Crane K, Kirby B, Cooperman D. Patient compliance for psychotropic medications: a group model for an expanding psychiatric inpatient unit. J Psychosoc Nurs. (1996); 34(1): 8-15.

32. Carson V. Mental Health Nursing: The Nurse-Patient Journey. $2^{\text {nd }}$ ed. Philadelphia: W.B. Saunders Co; (2000).

33. Mohr W. Johnson's psychiatric mental health nursing. $5^{\text {th }}$ ed. Philadelphia: Lippincott Williams \& Wilkins Co; (2003).

34. McFarland G, Thomas M. Psychiatric mental health nursing: application of the nursing process. Philadelphia: J.B. 
Lippincott Col (1991).

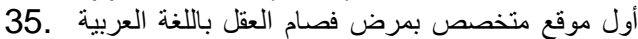

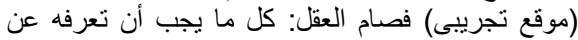

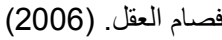

36. Brochure Lilly Egypt Company. ماذا يجب أن تعرف عن مرض الفصام وعلاجه. Cairo. (2001).

37. Kaptein A, Weinman J. Health psychology. UK: BPS Blackwell Co. (2004).

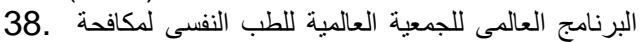

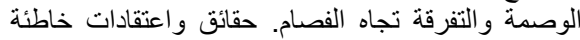

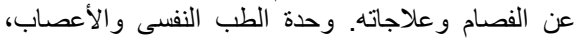
كلية الطب. جامعة القاهرة. (2001)

39. Al-Yahri A. Stigma of mental illness. Unpublished Master thesis. Faculty of Medicine. Ain Sams University. (1991).

40. Brunton K. Stigma. J Adv Nurs. (1997); 26: 891-8.

41. Corrigan $P$, Green $A$, Lundin R, Kubiak $M$, Penn D. Familiarity with and social distance from people who have serious mental illness, Psychiatr Serv. (2001); 52(7): 953-8.

42. Angermeyer $M$, Matschinger $H$. Causal beliefs and attitudes to people with schizophrenia: trend analysis based on data from two population surveys. $\mathrm{Br} \mathrm{J}$ Psychiatry. (2005); 186: 331-4.

43. Corrigan $\mathrm{P}$, Watson A. Understanding the impact of stigma on people with mental illness. World Psychiatry. (2002); 1(1): 16-9.

44. Kumar $T$, Sims A. Insight and its measurement in relation to psychosis: a review. (2001). Available from:http://bjp.rcpsych.org/cgi/content/full .2004.

45. Birchwood M, Smith J, Drury V, Healy J, Macmillan F, Slade M. A self-report insight scale for psychosis: reliability, validity and sensitivity to change. Acta Psychiatr Scand. (1994); 89:62-7.

46. Amador $X$, Seckinger $R$. The assessment of insight: a methodological review. Psychiatric Annals. (1997); 27(12): 798-805.

47. Brown C, Wright R, Christensesn D. Association between type of medication instruction and patients knowledge, side effects, and compliance. Hosp Community Psychiatry. (1987); 38: 5560.
48. Schaub R, Berghoefer A, MullerOerlinghausen $\mathrm{B}$. What do patients in a lithium outpatient clinic know about lithium therapy? Journal of Psychiatry \& Neuro Science. (2001); 26: 319-24.

49. Kelly G, Scott J, Mamon J. Medication compliance and health education among outpatients with chronic mental disorders. Medical Care. (1990); 28: 1181-97.

50. Goldman C, Quinn F. Effects of a patient education program in the treatment of schizophrenia. Hosp Community Psychiatry. (1998); 39: 282-6.

51. Dogan S, Sabanciogullari S. The effects of patient education in lithium therapy on quality of life compliance. Arch Psychiatr Nurs. (2003); 17(6): 270-5.

52. Davidoff S, Forester B, Ghaemi S, Bodkin J. Effect of video self-observation on development of insight in psychotic disorders. J Nerv Ment dis. (1998); 186(11): 697-700.

53. McEvoy J, Freter S, Merritt M, Apperson L. Insight about psychosis among outpatients with schizophrenia. Hosp Community Psychiatry. (1993); 44(9): 883-4.

54. Seltzer A, Roncar I, Garfinkel P. Effect of patient education on medication compliance. Can J Psychiatriy. (1980); 25: 638-45.

55. MacPherson R, Jerrom B, Hughes A. A controlled study of education about drug treatment in schizophrenia. $\mathrm{Br} J$ Psychiatry. (1996); 168: 709-17.

56. Batey S, Ledbetter J. Medication education for patients in a partial hospitalization program. JPNMHS. (1982); 20(7): 7-10.

57. Whiteside S. Patient education: effectiveness of medication programs for psychiatric patients. JPNMHS. (1983); 21(10): 17-21.

58. Lysaker $\mathrm{P}$, Bell M. Work rehabilitation and improvements in insight in schizophrenia. J Nerv Ment Dis. (1995); 183(2): 103-6. 